\title{
The benefit of running maintenance habituation before learning of machining process begins
}

\author{
Thomas Sukardi ${ }^{1}$ * (D), Bayu Rahmat Setiadi 1 (D), Afri Yudantoko ${ }^{2}$ \\ ${ }^{1}$ Universitas Negeri Yogyakarta, Indonesia. \\ ${ }^{2}$ Technische Universität Dresden, Germany. \\ * Corresponding Author. Email: thomas_sukardi@uny.ac.id
}

\section{ARTICLE INFO}

\section{Article History}

Received:

24 September 2021;

Revised:

21 November 2021;

Accepted:

3 December 2021;

Available online:

3 January 2022

\section{Keywords}

Classroom action

research;

Learning practices;

Running maintenance;

Teaching learning

\begin{abstract}
The study was aimed at investigating the advantages of the habituation of running maintenance and supervision over the practice learning process and the learning achievement of the students of Mechanical Engineering Study Program, Faculty of Engineering, Universitas Negeri Yogyakarta. It was participatory classroom action research. The subjects were 80 third-semester students grouped into the group $\mathrm{C}$ class. The data on the habituation of running maintenance were collected using a questionnaire; those on the students' learning achievement were collected through documentation and analyzed using a descriptive technique; those on the supervision intensity and machine feasibility were gathered through observations and analyzed using the descriptive qualitative technique. The findings showed that: 1.) The implementation of running maintenance used the systems of coaching, mentoring, and supervision with an optimal intensity of lecturers in teachinglearning machining practices; 2.) The habituation of running maintenance was done through standard procedures, and the implemented action took three cycles; 3.) The achievement of the habituation of running maintenance on students during the implementation of teaching-learning practices was characterized by the rapid job sheet completion that must be taken in one semester; and 4.) With the habituation of running maintenance, the feasibility of the existing machines in the workshop could be maintained.
\end{abstract}

This is an open access article under the $\underline{\mathrm{CC}-\mathrm{BY}-\mathrm{SA}}$ license.

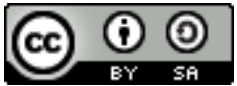

How to cite:

Sukardi, T., Setiadi, B. R., \& Yudantoko, A. (2021). The benefit of running maintenance habituation before learning of machining process begins. Jurnal Pendidikan Vokasi, 11(3), 222-231.

https://doi.org/10.21831/jpv.v11i3.44018

\section{INTRODUCTION}

Educational institutions, especially those which are related to technology fields, require adequate facilities for practicum teaching and learning. This means the capacity and diversity should be met in accordance with the competence demands that students must master. Thus, educational institutions are always required to prepare practicum facilities that students will use. On the one hand, technological advances are unstoppable to affect the aspects of human life. It is viewed from the technology used around us, ranging from equipment/machinery or industrial goods that are mechanical, electrical to sophisticated or robotics.

Educational institutions always procure practicum facilities in the form of tools or machines. Even they compete to get funded for the procurement of such practicum facilities. These institutions compete to buy the facilities for investment reasons without noticing their quality and origin 
(Asiabaka, 2008). However, the aspects of maintenance and repair are ignored so that the practicum facilities cannot function and work optimally.

Maintenance is considered an action that wastes time, energy, and cost (Firdaus et al., 2019). Some even argue that the treatment will be implemented only if the machines or tools are broken and not well-functioned. Those assumptions are incorrect because, as technicians, we have to remember that the investments use enormous amounts of money and can be regarded as an asset to be maintained. Also, we have to remember that saving the asset can be done by implementing programmed and scheduled maintenance (Hardt et al., 2021). According to Goyal and Maheshwari (2012), the function of maintenance in the manufacturing industry is to make its proper contribution to profits, productivity, and quality. It must be recognized as an integral part of the production strategy.

Educational institutions should realize the importance of the existence and role of maintenance in ensuring the continuity, smoothness, and stability of the process of an educational activity (Ekpoh, 2018). Based on a field experience, the abandonment of the maintenance generally resulted from the existing bureaucratic procedures in the institution itself, especially the different opinions from the existing management elements within the institution. Solving maintenance problems needs an approach that takes into account all aspects of the existing functions within the educational institution. A maintenance system should use a systematic approach that includes categories of management techniques, administrative procedures, technological practices, maintenance personnel management, and implementation controls. Of course, in the implementation, all these five elements cannot be applied simultaneously, but at least there is a combination among the five elements or adaptation based on the needs. In the Faculty of Engineering, Universitas Negeri Yogyakarta, especially in the Department of Mechanical Engineering Education, practicum facilities consist of machine tools, cutting tools, and measuring tools. There are 83 machine tools in total, consisting of 13 milling machines, 40 lathe machines, eight snap machines, 12 grinding machines, seven drilling machines, two slot machines, and one electric discharge machine (EDM).

The observation result in the workshop showed that of 83 machine tools, 14 machines or about $17 \%$ of the total machines in the machining workshop at the Department of Mechanical Engineering Education had been severely broken. The damages have an impact on the implementation of the practicum. The impact is a disruption of the students' achievement in mastering the machining competence. From the analysis of the observation results, it is found that the ineffective implementation of maintenance causes the damages of the machine tools. The maintenance that should run on a regular basis cannot be done properly because there is no maintenance schedule, fund, or culture in the students.

Most students do not fully understand the role of maintenance because they do not know the benefits of maintenance. The results of preliminary observations showed that $85 \%$ of students never did an inspection, initial setup, running maintenance lubrication, and repair of the machine to be used. Such conditions may affect the work performance of the students. For instance, the resulting workpiece of the product deviates from a predetermined standard. The condition is also worsened by ineffective supervision conducted by the lecturers/instructors who are responsible for the practice learning process. In addition, preliminary observation results showed that $90 \%$ of lecturers or instructors were not well-managed in conducting guidance, mentoring, and supervision to the students related to the maintenance.

Due to some problems such as the condition and the limited number of the machines, the broken machines, and the insufficient funds for maintenance, the readiness of practicum facilities is not well-achieved. As a result, the ratio of the machine and the students is too high, so that two or three students can use one machine. In other words, the available machines or tools cannot serve the learning process optimally. Sukardi's et al. (2013) research showed that the preventive maintenance culture had a good impact on the students' achievement in their learning practicum, as shown by the job sheet completion that can be achieved two times faster. In addition, the preventive maintenance done in the machining workshop positively impacted the feasibility of machine tools used by the students. The results of this study indicated that preventive maintenance needed to be planned, scheduled, and conducted by every student who would carry out machining practices in the workshop.

To improve the students' understanding of the maintenance function, it is necessary to train those who will carry out machining practices. Therefore, this study applied the culture or habit of 
running maintenance in the machining practices to the students in the Mechanical Engineering Study Program, Faculty of Engineering, Universitas Negeri Yogyakarta. Running maintenance is one of the preventive maintenance activities. If this activity is done regularly, the machine is expected to be durable and always ready to use. In implementing it, lecturers are required to be active in assisting, monitoring, supervising, and guiding the students to do it.

The practice learning process at the Mechanical Engineering Education Department, Faculty of Engineering, Universitas Negeri Yogyakarta requires sufficient, well-planned, and structured facilities and procedures. Its implementation requires seriousness and commitment either at the managerial or operational levels. In the implementation, many obstacles are found, such as 1.) The lack of practicum facilities; 2.) Many broken facilities since there is no maintenance; 3 .) The undone running maintenance program; 4.) The lack of funds for the practice learning process; 5.) The low competence of lecturers or instructors; 6.) The lack of commitment of existing human resources (lecturers, instructors, technicians, and managers); 7.) The ineffective management and process of practicum learning in the workshop; 8.) The uneven early provisions of the students; and 9.) The students' sincerity and work ethic do not support during the practice learning process.

The focused problem of this research is limited to the aspects of the practice learning process concerning the issue of the habituation of running maintenance in the students and the supervision intensity by the lecturer or instructor (lecturer's commitment and competence in teaching). The research problems can be formulated as follows: 1.) What is the implementation of running maintenance and supervision intensity in the practice learning process like?; 2.) What is the result of the habituation of running maintenance in the students during the implementation of the teaching and learning process of machining practices?; 3.) What is the result of the habituation of running maintenance in the students' learning outcomes during the practicum?; and 4.) What is the achievement of the habituation of running maintenance on the feasibility of machine tools in the workshop?

Therefore, the objective of this research is to reveal the implementation of running maintenance and supervision intensity in practicum teaching and learning, the achievement of the habituation of running maintenance in the students, the result of the habituation of running maintenance in the students' learning outcomes in the practicum, and the result of the habituation of running maintenance on the feasibility of machine tools in the workshop. The results of this study are expected to provide an overview and input in the implementation of the maintenance running culture and the supervision on the practice learning process at the Mechanical Engineering Education Department, Faculty of Engineering, Universitas Negeri Yogyakarta.

\section{Literature Review}

Maintenance often used in factories, workshops, or laboratories has two basic meanings: preservation and repair. Maintenance is defined as an activity to maintain and fix all facilities used to keep them durable and ready to use at any time, while the repair is a refreshment activity of all processes that have been broken or disrupted so that the facilities are able to function properly as the prior condition (Hantoro \& Sukardi, 1990). According to the dictionary, the term maintenance has the meaning of preservation or repair. However, in the factory or industry, maintenance is defined as a combination of all actions or activities performed in order to maintain the machine performance in normal conditions.

Maintenance is defined as an act of keeping machines or tools to make them stay in a normal condition and able to function properly (Gackowiec, 2019). According to ISO 14224:2016, maintenance has been defined as the combination of technical and associated administrative actions intended to retain an item or system or restore it to a state where it can perform its required function. According to Gandhare and Akarte (2012), the key objective of maintenance is to ensure system function (availability, efficiency, and product quality), system life (asset management), and system safety with low energy consumption. Related to this, the operational activities to be performed are conducting a routine inspection, setting the function of machines/tools routinely, performing daily lubrication, and cleaning tools. Whereas "repair" is defined as an activity to fix all machine components or equipment that has been broken due to certain uses (e.g., it is used for production). Under operational conditions, these repair activities may include minor repair, major repair, and even overhaul. Thus, in general, the main activity of maintenance is to maintain the continuity of the 
production process by conducting a regular inspection, repair, and overhaul. Figure 1 shows an overview related to crucial maintenance.

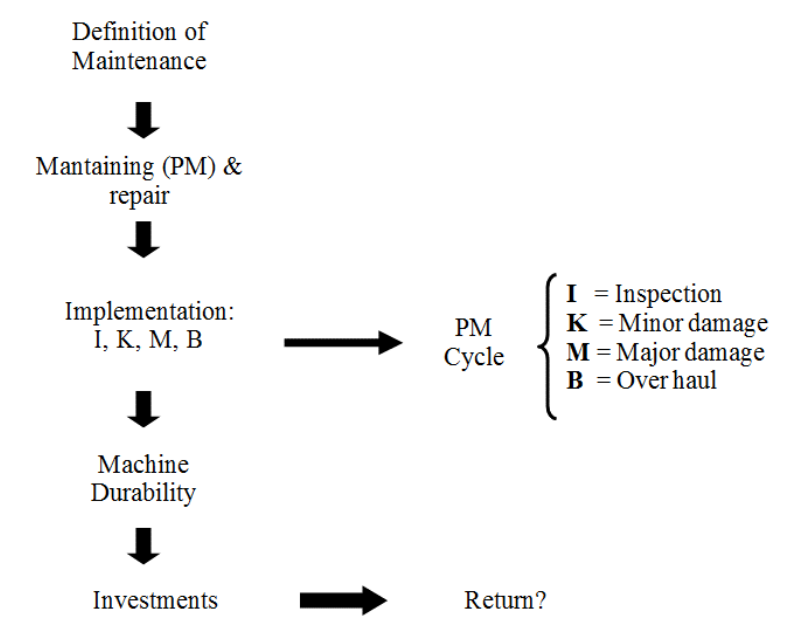

Figure 1. An Overview of the Crucial Maintenance

Maintenance is actually a combination of various activities aimed at keeping the machines or tools in good condition and serviceable to the users. Thus, the main objectives of maintenance activities according to Prokopenko and North (1996) are 1.) To optimize the reliability of equipment and infrastructure; 2.) To ensure that equipment and infrastructure are always in good condition; 3. ) To carry out prompt emergency repair of equipment and infrastructure so as to secure the best possible availability for production; 4.) To enhance, through modifications, extensions, or new lowcost items, the productivity of existing equipment or production capacity; 5 .) To ensure the operation of equipment for production and for the distribution of energy and fluids; 6.) To improve operational safety; 7.) To train personnel in specific maintenance skills; 8.) To advise on the acquisition, installation and operation of machinery; 9.) To contribute to finished product quality; and 10.) To ensure environmental protection. In order to support the production activities, machine operators need to understand the philosophy of maintenance.

Thus, what should be done in the implementation of maintenance should be in accordance with the expectations. On the other side, the quality of the final product is affected by both the production process and the quality of maintenance (Pophaley \& Vyas, 2010). There are several things to consider in implementing and controlling the maintenance of machines or tools. Those things are 1.) The implementation and habituation of routine maintenance such as heating machine or tool (running maintenance); 2.) The regular inspection of machinery or tools; 3.) The implementation of preventive maintenance, including periodic inspections, periodic inspection reports, periodic replacement of components, periodic settings, and testing; 4.) The participation of workers or operators in maintenance activities; 5.) The administration of maintenance and repair of machines or tools; and 6.) The planning and approval of the maintenance by institutions, factory managers, and supervisors (Dhillon, 2002).

People working in the maintenance section have to think about what they can give to other sections or about the determinants of the success of a maintenance section. The key to success is something that can support the maintenance in serving or providing other sections with appropriate. The key to success is the factors that should be owned by the maintenance people, which include: 1) Competent and skillful personnel; 2) Availability of machine/tool data; 3) Efficient flows of information; 4) Clear operational instructions; 5) Availability of a standard operating procedure; 6) Ability and willingness to make maintenance plans; 7) Self-discipline of personnel/workers/operators; 8) Awareness of maintenance personnel; 9) Safety and security at work; 10) Accuracy at work; 11) Adequate facilities at work; 12) Compatibility of work systems and procedures; and 13) Availability of funds and spare parts (Subiyono, 1993). 
Shanmugam and Robert (2015) said that the concept of human factors is used for the manage-ment of maintenance resources because human factors determine the success of maintenance. The concept is applied to shape the behavior and culture of safety in the workplace. Human factors in maintenance are a pressing problem. The framework fields important insights regarding the influence of human factors in maintenance decision-making. By incorporating various approaches, a strong framework for analyzing human factors is very important in maintenance, a culture of maintenance will be created well (Sheikhalishahi et al., 2016).

Operationally, maintenance activities are divided into two main activities, namely planned maintenance and unplanned maintenance. The planned maintenance consists of preventive maintenance and corrective maintenance. There are two types of activities in preventive maintenance, namely maintenance in the form of heating machines or tools (running maintenance) (Gackowiec, 2019) and maintenance that must stop the activities of all machines in a moment related to the addition of components or shutdown maintenance (Garg \& Gupta, 1987). Furthermore, corrective maintenance is an activity that can be divided into two. They are reparation because of damages and overhaul (breakdown maintenance). In addition, unplanned maintenance is usually done because of damages to the part of the machines or tools, which are very important in the factory (emergency maintenance). For more details, see the following flow chart as shown in Figure 2.

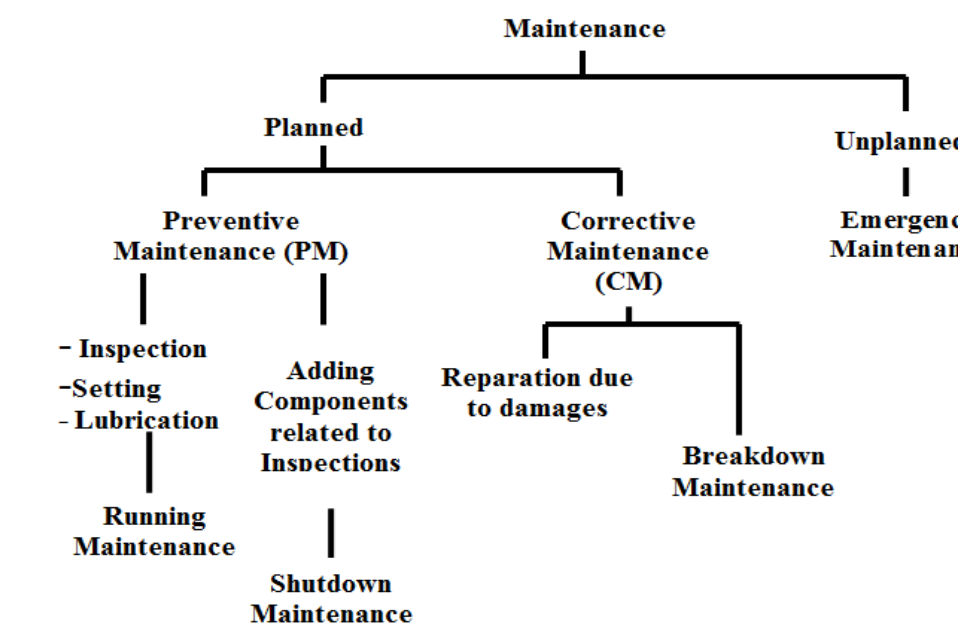

Figure 2. A Flow Chart of the Maintenance Type of Machines

\section{RESEARCH METHOD}

This study examines the implementation of the habituation of running maintenance and the supervision conducted by the lecturer in the practicum class. This study is classroom action research with direct participants (participatory action research). It is conducted by providing a direct involvement of researchers from the beginning to the end of the process as a form of class problem-solving actions. The main concept of action research, according to Lewin, consists of four stages, namely: 1.) Planning; 2.) Acting; 3.) Observing, and 4.) Reflecting.

The research was conducted in the workshop of the Mechanical Engineering Education Department for four months. The population consisted of the students of the Mechanical Engineering Department, Faculty of Engineering, Universitas Negeri Yogyakarta, and the sample consisted of 80 students in their third semester. The data on the culture of running maintenance were collected using a questionnaire. The data on the supervision intensity and machine feasibility were gathered through observations, while the data on the practice learning process achievement were collected from the lecturer's documentation, and the other data were collected through direct observation on the practicum.

The data from the questionnaire and those on the students' learning achievement in the practicum were analyzed by employing a descriptive technique, while those from the interviews and observations were analyzed by using a qualitative descriptive technique to explain in detail all 
phenomena obtained from the field. The action undertaken in this study refers to a model of an activity developed by Lewin. The cycles are: planning, implementation, observation, and analysis and reflection. Planning phase identified the materials of the habituation of running maintenance through various literature studies, relevant journals, and websites. The setting of the running maintenance materials was done to select and sort the materials used according to the time and topic of the practice learning process. The tryout of the habituation of running maintenance to the students was conducted at Implementation stage. The students were observed during the learning process, including how they performed the habituation of running maintenance.

At the observation stage, lecturers conducted the observation of the supervision intensity in order to implement the habituation of running maintenance. The lecturers supervised, controlled, and monitored the students' activities in order to implement the habituation of running maintenance. This observation was conducted to ensure that there was no misconduct during the implementation. The last stage is analysis and reflection which is done by evaluating, revising, and correcting if there is a discrepancy in the material, time, and teacher. The lecturers did the observations on the supervision to ensure that the students had performed the habituation of running maintenance.

\section{RESULT AND DISCUSSION}

The observation prior to the implementation of the model resulted in the data on the machine damage. The data were related to the frequency and location of the damage. The data on the damage frequency showed machine damage during its use every day. The location of the damage was the location of the component, which frequently experienced damages every day. Table 1 shows the damage of components of various types of machines commonly used by students for practicum. Before the running maintenance program was implemented, the damage frequency was irregular, starting from once to four times a day. After the running maintenance program was implemented, the damage could be reduced to once a day, especially for shaping, lathe, and milling machines. In addition, the damages were mainly found only on the components that were often used. The implementation of a running maintenance program had a positive impact, i.e., machine damages could be minimized. The culture of running maintenance could be well achieved through three cycles. However, this process still could not deliver optimal results; some aspects had not been instilled in the students. For more details, see Table 2.

Table 2 explains that the implementation of running maintenance can be completed in 3 cycles. In the first cycle, $\pm 62.5 \%$ of the aspects had not been well implemented, especially in alignment, adjustment, lubrication, and some inspection aspects $( \pm 12.5 \%)$. This means that the students had not understood and could not interpret the importance of running maintenance. For further actions, the teachers should provide guidance and assistance intensively to the students by sharpening the meaning and benefits of running maintenance.

In Cycle 2, the success rate reached $62.5 \%$, meaning that there was a very significant improvement compared to that reached in Cycle 1. The most notable aspect that was not implemented was the alignment aspect (18.75\%), $12.5 \%$ in the adjustment aspect, $6.5 \%$ in the lubrication aspect. Thus, in Cycle 2 there was $\pm 37.5 \%$ of the aspects that were not implemented. This means that in this cycle, the students started to play a role in the implementation of running maintenance.

In Cycle 3, the implementation of running maintenance could be done well; the students could already feel the benefits of this activity. All aspects, namely inspection, alignment, adjustment, and lubrication, ran well. One aspect of lubrication had not run yet, i.e., giving grease $( \pm 6.25 \%$ out of $12.5 \%$ of lubrication aspect), and there were aspects that were not yet implemented optimally in the adjustment aspect. These aspects did not run well because the facilities used for lubrication and adjustment were inadequate; thus, they were not implemented.

In addition to the decreasing frequency of damage to the machine, implementing the habituation of running maintenance also affects the students' speed in completing the job. As shown in Table 3, treatment groups 1 and 2 can complete five jobs in 8 weeks of practicum. While the control groups: class B1.1 \& B1.2 can complete only $2-4$ jobs in 8 weeks, classes C1.1 \& C 1.2 can complete 2 - 3 jobs in 8 weeks, so can classes B2 .1 \& B2.2, 2 - 3 jobs in 8 weeks. The differences 
in the number of jobs done are because the treatment group always performs running maintenance first before carrying out the practice.

Table 1. The Damage Frequency on Machines

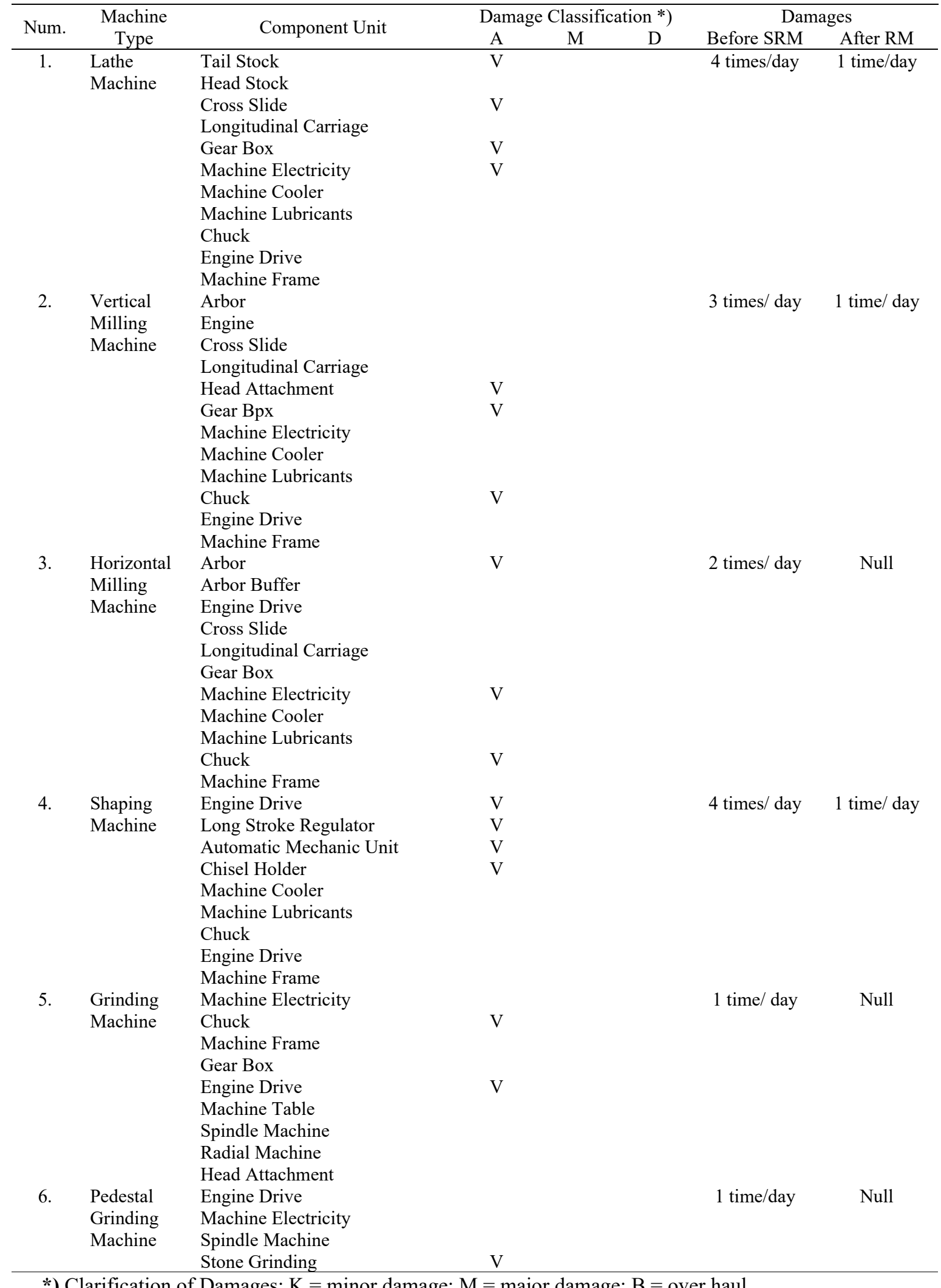

*) Clarification of Damages: $\mathrm{K}$ = minor damage; $\mathrm{M}$ = major damage; $\mathrm{B}$ = over haul 
Table 2. The Habituation of Running Maintenance of the Treatment Group

\begin{tabular}{|c|c|c|c|c|}
\hline Num. & Running Maintenance Aspects & Reflection on Cycle 1 & Refelection on Cycle 2 & Reflection on Cycle 3 \\
\hline \multirow{7}{*}{1.} & Inspection & & & \\
\hline & $\begin{array}{l}\text { - Checking the machine's } \\
\text { electrical system }\end{array}$ & Implemented & Implemented & Implemented \\
\hline & $\begin{array}{l}\text { - Checking and trying the } \\
\text { handle function }\end{array}$ & Implemented & Implemented & Implemented \\
\hline & $\begin{array}{l}\text { - Checking the machine's } \\
\text { indicator system }\end{array}$ & Implemented & Implemented & Implemented \\
\hline & $\begin{array}{l}\text { - Checking the machine's } \\
\text { work functions }\end{array}$ & Not implemented & Implemented & Implemented \\
\hline & - Checking the fragile parts & Not implemented & Implemented & Implemented \\
\hline & $\begin{array}{l}\text { - Checking the binding system } \\
\text { Alignment }\end{array}$ & Implemented & Implemented & Implemented \\
\hline \multirow{5}{*}{2.} & $\begin{array}{l}\text { - Setting the motion's } \\
\text { conformity }\end{array}$ & Not implemented & Not implemented & $\begin{array}{l}\text { Not yet optimally } \\
\text { implemented }\end{array}$ \\
\hline & - Setting the motion's equality & Not implemented & Implemented & $\begin{array}{l}\text { Not yet optimally } \\
\text { implemented }\end{array}$ \\
\hline & $\begin{array}{l}\text { - Setting the motion's } \\
\text { uprightness }\end{array}$ & Not implemented & Not implemented & Implemented \\
\hline & $\begin{array}{l}\text { - Setting the moving } \\
\text { component's joint and } \\
\text { alignment }\end{array}$ & Not implemented & Not implemented & Implemented \\
\hline & $\begin{array}{l}\text { - Setting the joint, alignment } \\
\text { and moving components }\end{array}$ & Not implemented & Implemented & Implemented \\
\hline \multirow{5}{*}{3.} & Adjustment & & & \\
\hline & $\begin{array}{l}\text { - Checking the component's } \\
\text { position }\end{array}$ & Not implemented & Not implemented & Implemented \\
\hline & - Adjusting the sliding motion & Not implemented & Not implemented & Implemented \\
\hline & $\begin{array}{l}\text { - Checking and adjusting } \\
\text { clamps }\end{array}$ & Implemented & Implemented & Implemented \\
\hline & $\begin{array}{l}\text { - Checking and adjusting aids } \\
\text { Lubrication }\end{array}$ & Implemented & Implemented & Implemented \\
\hline \multirow[t]{2}{*}{4.} & $\begin{array}{l}\text { - Checking and adding } \\
\text { lubricants }\end{array}$ & Not implemented & Implemented & Implemented \\
\hline & $\begin{array}{l}\text { - Applying grease on some } \\
\text { parts in need }\end{array}$ & Not implemented & Not implemented & Not implemented \\
\hline
\end{tabular}

Table 3. Students' Task Accomplishment

\begin{tabular}{ccccccccccc}
\hline \multirow{2}{*}{ No. } & \multirow{2}{*}{ Group } & 1 & 2 & 3 & 4 & 5 & 6 & 7 & 8 & Note \\
\hline 1 & Treatment Group 1 & v & v & v & v & v & & & Accomplished in Week 8 71.42\% \\
2 & Treatment Group 2 & v & v & v & v & v & & & Accomplished in Week 8 71.42\% \\
3 & B1.1 \& B1.2 Group & v & v & v & v & & & & Accomplished in Week 8 50\%\% \\
4 & B2.1 \& B2.2 Group & v & v & & & & & & Accomplished in Week 8 20\% \\
5 & C2.1 \& C2.2 Group & v & v & v & & & & Accomplished in Week 8 37.5\% \\
\hline
\end{tabular}

The inspection of machines enables the lecturers to know the function of components and the positions among components so that the students can replace or adjust the machine components to function perfectly. For example, whether the machine is suitable for use can be determined by checking the machine's electrical system, handle function, indicator system, work function, fragile parts, and binding system. The treatment group always performs running maintenance so that the machine is always in proper condition and works according to the machine's geometric quality, resulting in a higher quantity of jobs than that of the control group. 


\section{CONCLUSION}

The following conclusions can be drawn from the results of this classroom action research in the implementation of running maintenance. The implementation pattern of running maintenance employs guidance, mentoring, and supervision systems with optimal intensity by lecturers in machining practices' teaching and learning process. The habituation of running maintenance can be done well in three cycles. All running maintenance aspects such as inspection, alignment, adjustment, and lubrication are running well. Some parts of lubrication aspects have not been implemented, i.e., applying grease $(6.25 \%$ out of $12.5 \%$ of the total lubrication aspect), and some adjustment aspects are not optimally implemented to the lack of facilities for lubrication and adjustment. Other results also reveal that the student's achievement on the habituation of running maintenance during the implementation of the practical teaching and learning process is marked by the fast completion of the job sheets they take in 1 semester. With the habituation of running maintenance, the feasibility of machining tools in the workshop can be maintained well, marked by the lack of damage to the machine during the practicum activities.

\section{REFERENCES}

Asiabaka, I. P. (2008). The need for effective facility management in schools in Nigeria. New York Science Journal, $1(2)$, http://www.sciencepub.net/newyork/0102/02_0366_Asiabaka_FACILITIES.pdf

$10-21$.

Dhillon, B. S. (2002). Engineering maintenance: a modern approach. CRC Press. https://books.google.com/books?hl=en\&lr=\&id=vfHKBQAAQBAJ\&oi=fnd\&pg=PP1\&dq $=$ Engineering + maintenance $: \mathrm{A}+$ Modern + approach\&ots $=6$ uwiqy $4 \mathrm{iYj} \& \operatorname{sig}=\mathrm{hYDJOHuW}$ X2BFqFKE-Y7xGcJhz8

Ekpoh, U. I. (2018). School plant maintenance culture and utilization. In N. P. Ololube (Ed.), Handbook of Research on Educational Planning and Policy Analysis (pp. 138-155). Pearl Publishers. https://www.researchgate.net/profile/Uduak-Ekpoh2/publication/332803962_School_Plant_Maintenance_Culture_and_Utilization/links/5ccae 6ea92851c8d22146cb2/School-Plant-Maintenance-Culture-and-Utilization.pdf

Firdaus, N., Samat, H. A., \& Mohamad, N. (2019). Maintenance for energy efficiency: a review. IOP Conference Series: Materials Science and Engineering, 530(1), 1-15. https://doi.org/10.1088/1757-899X/530/1/012047

Gackowiec, P. (2019). General overview of maintenance strategies-concepts and approaches. Multidisciplinary Aspects of Production Engineering, 2(1), 126-139. https://doi.org/10.2478/mape-2019-0013

Gandhare, B. S., \& Akarte, M. (2012). Maintenance strategy selection. Ninth AIMS International Conference on Management, January, 1330-1336. https://www.researchgate.net/profile/BalasahebGandhare/publication/267298504_Maintenance_Strategy_Selection/links/571 ee43708aeac ed7889e9ec/Maintenance-Strategy-Selection.pdf

Garg, H. P., \& Gupta, B. P. (1987). Industrial maintenance. S. Chand Limited. https://www.google.co.id/books/edition/Industrial_Maintenance/Hh9gPQAACAAJ?hl=en

Goyal, R. K., \& Maheshwari, K. (2012). Maintenance management practices: a retrospective and literature review. International Journal of Advances in Engineering Research, 3(2), 49-66. https://ijaer.com/admin/upload/06 Feb_2012_Ravi Kumar Goyal.pdf

Hantoro, S., \& Sukardi, T. (1990). Teknologi pemeliharaan mesin perkakas (1st ed.). Liberty. https://opac.perpusnas.go.id/DetailOpac.aspx?id=20018 
Hardt, F., Kotyrba, M., Volna, E., \& Jarusek, R. (2021). Innovative approach to preventive maintenance of production equipment based on a modified TPM methodology for industry 4.0. Applied Sciences, 11(15), 6953. https://doi.org/10.3390/app11156953

Pophaley, M., \& Vyas, R. K. (2010). Plant maintenance management practices in automobile industries: a retrospective and literature review. International Journal of Advances in Engineering Research, https://doi.org/http://dx.doi.org/10.3926/jiem.v3n3.p512-541 $3(3)$, $512-541$.

Prokopenko, J., \& North, K. (1996). Productivity and quality management: a modular programme. International Labour Office. https://books.google.co.id/books?id=dw\%5C_CtAEACAAJ

Shanmugam, A., \& Robert, T. P. (2015). Human factors engineering in aircraft maintenance: a review. Journal of Quality in Maintenance Engineering, 21(4), 478-505. https://doi.org/10.1108/JQME-05-2013-0030

Sheikhalishahi, M., Pintelon, L., \& Azadeh, A. (2016). Human factors in maintenance: a review. Journal of Quality in Maintenance Engineering, 22(3), 218-237. https://doi.org/10.1108/JQME-12-2015-0064

Subiyono, S. (1993). Manajemen Perawatan. Polman.

Sukardi, T., Marwanto, A., \& Ngadiyono, Y. (2013). Pengembangan model running maintenance pada proses pemesinan di Jurusan Mesin SMK Rumpun Teknologi se-DIY. https://eprints.uny.ac.id/22708/1/LAPORAN AKHIR BURNING, THOMAS.pdf 